\title{
Use of rhBMP-2 for adult spinal deformity surgery: patterns of usage and changes over the past decade
}

\author{
Mathieu Bannwarth, MD, ${ }^{1}$ Justin S. Smith, MD, PhD, ${ }^{2}$ Shay Bess, MD, ${ }^{3}$ Eric O. Klineberg, MD, ${ }^{4}$ \\ Christopher P. Ames, MD, ${ }^{5}$ Gregory M. Mundis Jr., MD, ${ }^{6}$ Han Jo Kim, MD, ${ }^{7}$ Renaud Lafage, MS, ${ }^{7}$ \\ Munish C. Gupta, MD, ${ }^{8}$ Douglas C. Burton, MD, ${ }^{9}$ Christopher I. Shaffrey, MD, ${ }^{10}$ \\ Frank J. Schwab, MD, ${ }^{7}$ Virginie Lafage, $\mathrm{PhD},{ }^{7}$ and the International Spine Study Group (ISSG)
}

1'Department of Neurosurgery, University Hospital of Reims, France; 2Department of Neurosurgery, University of Virginia Health System, Charlottesville, Virginia; ${ }^{3}$ Rocky Mountain Scoliosis and Spine, Denver, Colorado; ${ }^{2}$ Department of Orthopaedic Surgery, University of California, Davis; ${ }^{5}$ Department of Neurological Surgery, University of California, San Francisco; ${ }^{6}$ San Diego Center for Spinal Disorders, La Jolla, California; 'Department of Orthopaedic Surgery, Hospital for Special Surgery, New York, New York; ${ }^{8}$ Washington University in St. Louis, Missouri; ${ }^{9}$ Orthopaedic Surgery, University of Kansas Medical Center, Kansas City, Kansas; and ${ }^{10}$ Departments of Neurosurgery and Orthopaedic Surgery, Duke University Medical Center, Durham, North Carolina

OBJECTIVE Recombinant human bone morphogenetic protein-2 (rhBMP-2) has been shown to increase fusion rates: however, cost, limited FDA approval, and possible complications impact its use. Decisions regarding rhBMP-2 use and changes over time have not been well defined. In this study, the authors aimed to assess changes in rhBMP-2 use for adult spinal deformity (ASD) surgery over the past decade.

METHODS A retrospective review of the International Spine Study Group prospective multicenter database was performed to identify ASD patients treated surgically from 2008 to 2018. For assessment of rhBMP-2 use over time, 3 periods were created: 2008-2011, 2012-2015, and 2016-2018.

RESULTS Of the patients identified, 1180 met inclusion criteria, with a mean age 60 years and $30 \%$ of patients requiring revision surgery; rhBMP-2 was used in $73.9 \%$ of patients overall. The mean rhBMP-2 dose per patient was $23.6 \mathrm{mg}$. Patients receiving rhBMP-2 were older (61 vs 58 years, $p<0.001$ ) and had more comorbidities (Charlson Comorbidity Index 1.9 vs 1.4, $p<0.001$ ), a higher rate of the Scoliosis Research Society-Schwab pelvic tilt modifier (>0;68\% vs $62 \%$, $p=0.026$ ), a greater deformity correction (change in pelvic incidence minus lumbar lordosis $15^{\circ}$ vs $12^{\circ}, p=0.01$ ), and more levels fused ( 8.9 vs $7.9, p=0.003$ ). Over the 3 time periods, the overall rate of rhBMP-2 use increased and then stabilized (62.5\% vs $79 \%$ vs $77 \%$ ). Stratified analysis showed that after an overall increase in rhBMP-2 use, only patients who were younger than 50 years, those who were smokers, those who received a three-column osteotomy (3CO), and patients who underwent revision sustained an increased rate of rhBMP-2 use between the later two periods. No similar increases were noted for older patients, nonsmokers, primary surgery patients, and patients without a $3 \mathrm{CO}$. The total rhBMP-2 dose decreased over time ( $26.6 \mathrm{mg}$ vs $24.8 \mathrm{mg}$ vs $20.7 \mathrm{mg}, \mathrm{p}<0.001)$. After matching patients by preoperative alignment, 215 patients were included, and a significantly lower rate of complications leading to revision surgery was observed within the 2012-2015 period compared with the 2008-2011 (21.4\% vs 13.0\%, $p=0.029)$ period, while rhBMP-2 was increasingly used ( $80.5 \%$ vs $66.0 \%, p=0.001)$. There was a trend toward a lower rate of pseudarthrosis for patients in the 2012-2015 period, but this difference did not reach statistical significance ( $7 \%$ vs $4.2 \%, p=0.283$ ).

CONCLUSIONS The authors found that rhBMP-2 was used in the majority of ASD patients and was more commonly used in those with greater deformity correction. Additionally, over the last 10 years, rhBMP-2 was increasingly used for ASD patients, but the dose has decreased.

https://thejns.org/doi/abs/10.3171/2021.3.FOCUS2164

KEYWORDS adult spinal deformity; arthrodesis; bone morphogenetic protein; fusion; instrumentation; pseudarthrosis; rhBMP-2; spine surgery

ABBREVIATIONS ALIF = anterior lumbar interbody fusion; $\mathrm{ASD}=$ adult spinal deformity; $\mathrm{BMP}=$ bone morphogenetic protein; $\mathrm{CCI}=\mathrm{Charlson}$ Comorbidity Index; EBL = estimated blood loss; ICBG = iliac crest bone graft; LLIF = lateral lumbar interbody fusion; ODI = Oswestry Disability Index; PI-LL = pelvic incidence minus lumbar lordosis; PLIF = posterior lumbar interbody fusion; PT = pelvic tilt; rhBMP-2 = recombinant human BMP-2; SRS = Scoliosis Research Society; SVA = sagittal vertical axis; TLIF = transforaminal lumbar interbody fusion; $3 \mathrm{CO}=$ three-column osteotomy.

SUBMITTED January 30, 2021. ACCEPTED March 17, 2021.

INCLUDE WHEN CITING DOI: 10.3171/2021.3.FOCUS2164. 
$\mathrm{A}$ CHIEVING a solid bony fusion is one of the primary goals when performing spinal arthrodesis. Historically, iliac crest bone graft (ICBG) has been the gold-standard grafting material for fusion, but the harvest of ICBG has been associated with relatively high rates of morbidity, including donor site pain. ${ }^{1}$ At the end of the 1990 s, very promising studies reported high rates of fusion and good clinical outcomes with the use of recombinant human bone morphogenetic protein-2 (rhBMP-2) as an adjunct for spinal fusion, 2,3 thereby avoiding the need to use ICBG. RhBMP-2 was approved by the US FDA in 2002, but only for use in a cage placed between the L4 and S1 spinal levels for anterior lumbar interbody fusion (ALIF). However, with promising results from the approved treatment use, off-label uses of rhBMP-2 for spinal fusion rapidly increased. As rhBMP-2 was more commonly used, reports of potentially associated adverse events emerged, including radiculitis, heterotopic bone formation, bone resorption, cancer-related risk, and retrograde ejaculation. ${ }^{4-9}$

In 2011, a controversial publication by Carragee et al. ${ }^{10}$ reported a possible design bias in the initial industry-sponsored studies, therefore questioning their validity. This led to the publication of numerous studies with high levels of evidence (randomized controlled trials and meta-analyses) designed to investigate the FDA-approved and off-label uses of rhBMP-2. ${ }^{11-15}$ These studies tried to apply stricter methodologies and had more qualified conclusions than the first industry-sponsored studies. ${ }^{13}$

Although multiple studies have assessed the application of rhBMP-2 for fusion in the setting of degenerative diseases treated with 1- or 2-level fusion, few have addressed its application to adult spinal deformity (ASD) surgery. ASD patients represent a unique patient population with a reported incidence of pseudarthrosis reaching $30 \%$ in the context of long fusion surgery. ${ }^{16}$ Lack of bony fusion in ASD can lead to instrumentation failure and the need for extensive revision surgery. ${ }^{17}$ Thus, off-label use of rhBMP-2 in the setting of ASD surgery has become increasingly popular and has demonstrated promising results, despite its continued high associated cost. ${ }^{18}$

The perceptions and reporting of the safety and efficacy of rhBMP-2 have evolved over time, and, even to the present, the decision of whether to use rhBMP-2 for ASD patients, who arguably stand to benefit the most, remains unsettled. Against this backdrop, it is interesting to evaluate how ASD surgeons have adapted their practices over time. This study aimed to assess applications and dosing of rhBMP-2 for ASD surgery in a large, prospectively collected series of patients from a group of experienced spinal deformity surgeons, and to highlight how these applications have changed over the past 10 years.

\section{Methods}

\section{Patient Population}

This study was performed as a retrospective review of a multicenter database of surgical ASD patients collected through the International Spine Study Group. Institutional review board approval was obtained at each site prior to study initiation. Seventeen participating sites located in the US contributed patients to the data set. Patient inclusion criteria for database entry were 1) age older than 18 years; and 2) at least one of the following radiographic findings of ASD: coronal Cobb angle greater than $20^{\circ}$, sagittal vertical axis (SVA) greater than $5 \mathrm{~cm}$, pelvic tilt (PT) greater than $25^{\circ}$, and thoracic kyphosis greater than $60^{\circ}$. Database exclusion criteria were spinal deformities due to neuromuscular, posttraumatic, neoplastic, rheumatological, and/or infectious disorders. The present study focused only on patients treated operatively for ASD for whom data regarding the use of rhBMP-2 were available.

\section{Data Collection}

Demographic data included age, sex, BMI, smoking status, comorbidities, and history of previous spine surgery. Patient-reported outcomes were assessed with the Oswestry Disability Index (ODI). Surgical characteristics included the number of levels fused, approach (posterior fusion only, posterior fusion combined with transforaminal lumbar interbody fusion [TLIF]/posterior lumbar interbody fusion [PLIF], or posterior fusion combined with ALIF/lateral lumbar interbody fusion [LLIF]), use of three-column osteotomy (3CO), operative time, and estimated blood loss (EBL). Full-length free-standing radiographs were obtained at baseline and immediate follow-up, and the Scoliosis Research Society (SRS)Schwab classification was determined.${ }^{19}$ Data collected for rhBMP-2 included whether or not it was used, the location of use (all fusion points, posterior, TLIF/PLIF, and ALIF/ LLIF), and dose (total, per level, and per location). Finally, complications and revision surgery data were collected.

\section{Statistical Analysis}

A descriptive analysis of the entire cohort was first performed for demographic data, radiographic measures, surgical parameters, and the use of rhBMP-2 by approach. $\mathrm{Pa}-$ tients who received rhBMP-2 (BMP) were compared with those treated without rhBMP-2 (no-BMP). Comparisons of demographics, ODI score, preoperative SRS-Schwab classification, and surgical parameters between BMP and no-BMP patients were performed using the chi-square test or Student t-test as appropriate.

For assessment of rhBMP-2 use over time, 3 periods were created: 2008-2011, 2012-2015, and 2016-2018. Using one-way ANOVA, these time periods were compared in terms of patient demographics, ODI score, preoperative SRS-Schwab classification, surgical parameters, incidence of rhBMP-2 use, and dose of rhBMP-2. Finally, a subanalysis of patients with a 2-year follow-up was conducted. Patients who underwent surgery in the 2008-2011 period were propensity-matched to those who underwent surgery in the 2012-2015 period based on preoperative pelvic incidence minus lumbar lordosis (PI-LL) and maximum coronal Cobb angle. Outcomes of these two periods were compared in terms of demographics, radiographic and surgical parameters, rhBMP-2 use, and postoperative complications. Patients were diagnosed with a pseudarthrosis when at least one of the following events led to a revision surgery: rod breakage, screw breakage, radiographic signs of pseudarthrosis, or dislodgment of screw/rod. 


\section{Results}

\section{Global Analysis}

From the database review, 1180 patients met inclusion criteria, with a mean \pm SD age of $60 \pm 14$ years, a mean BMI of $27.9 \pm 6.2 \mathrm{~kg} / \mathrm{m}^{2}$, and a majority (73.3\%) of female patients. The overall incidence of rhBMP-2 use was $73.9 \%$, with a mean total dose per patient of $23.6 \pm 16.6 \mathrm{mg}$ and a mean dose per vertebral level of $3.1 \pm 3.3 \mathrm{mg} / \mathrm{level}$ (Table 1). The analysis by approach revealed that $72.9 \%$ of patients with a posterior fusion received rhBMP-2 with a mean dose of $2.9 \pm 2.7 \mathrm{mg} / \mathrm{level}, 78.5 \%$ of patients with a combined fusion with TLIF/PLIF received rhBMP-2 with a mean interbody dose of $4.8 \pm 2.5 \mathrm{mg} / \mathrm{level}$ and a mean posterior dose of $3.4 \pm 3.1 \mathrm{mg} / \mathrm{level}$, and $71.5 \%$ of patients with a combined fusion with ALIF/LLIF received rhBMP-2 with a mean interbody dose of $4.0 \pm 2.7 \mathrm{mg} / \mathrm{level}$ and a mean posterior dose of $2.8 \pm 2.5 \mathrm{mg} /$ level.

\section{BMP Versus No-BMP Patients}

BMP patients were older $(61.1 \pm 13.1$ years vs $57.9 \pm$ 17.5 years, $\mathrm{p}<0.001)$, had a higher BMI $\left(28.1 \pm 6.3 \mathrm{~kg} / \mathrm{m}^{2}\right.$ vs $\left.27.2 \pm 5.9 \mathrm{~kg} / \mathrm{m}^{2}, \mathrm{p}=0.037\right)$, and had more comorbidities (Charlson Comorbidity Index [CCI] $1.9 \pm 1.7$ vs $1.4 \pm$ $1.6, \mathrm{p}<0.001)$. No differences were observed between the BMP and no-BMP patient groups regarding a history of cancer ( $12.7 \%$ vs $10.7 \%, \mathrm{p}=0.203)$, and no patient developed new malignancy after surgery during the follow-up.

No differences were observed in the rate of previous spine fusion or in pre- or postoperative ODI scores. Radiographically, BMP patients trended toward having worse preoperative sagittal alignment, with $67.9 \%$ and $61.9 \%$ of the BMP and no-BMP patients, respectively, having an SRS-Schwab PT modifier greater than $0(\mathrm{p}=0.026)$. No differences were observed in preoperative coronal alignment or postoperative alignment (coronal and sagittal) between the groups. BMP patients had a greater sagittal correction $\left(\triangle \mathrm{PI}-\mathrm{LL}: 15.3^{\circ} \pm 18.6^{\circ}\right.$ vs $12^{\circ} \pm 19.4^{\circ}, \mathrm{p}=0.010$; and $\Delta \mathrm{T} 1$ pelvic angle: $-7.8 \pm 10.8$ vs $-6 \pm 10.8, \mathrm{p}=0.011$ ).

Analysis of surgical parameters revealed that BMP patients had a longer operative time $(445.7 \pm 182.2$ minutes vs $390.4 \pm 192.6$ minutes, $\mathrm{p}<0.001)$, a greater EBL (1700 $\pm 1485 \mathrm{ml}$ vs $1382 \pm 1300 \mathrm{ml}, \mathrm{p}=0.001)$, a lower rate of $3 \mathrm{COs}(0.1 \pm 0.3$ vs $0.2 \pm 0.4 \mathrm{p}=0.012)$, and a higher number of vertebral levels fused ( $8.9 \pm 4.6$ vs $7.9 \pm 4.8, \mathrm{p}=$ 0.003). All results are reported in Table 2.

\section{RhBMP-2 Use Over Time}

The overall rate of rhBMP-2 use increased from $62.5 \%$ to $79.0 \%$ between the first two periods (2008-2011 and 2012-2015) and then stabilized at $79.0 \%$ to $77.0 \%$ between the last two periods (2012-2015 and 2016-2018). The stratification by parameters of interest (age, smoking status, cancer history, primary/revision surgery, fusion approach, and use of 3CO) revealed an overall increase in rhBMP-2 use between the first two periods, except for patients younger than 50 years of age (no change). Between the last two periods, the analysis showed that only younger patients, smokers, patients who received a $3 \mathrm{CO}$, and patients who underwent revision sustained an increased rate of rhBMP-2 use. In contrast, the rate of rhBMP-2
TABLE 1. Global cohort description

\begin{tabular}{|c|c|}
\hline & Value \\
\hline No. of patients & 1180 \\
\hline Mean age, yrs & $60.2 \pm 14.4$ \\
\hline Mean BMI, $\mathrm{kg} / \mathrm{m}^{2}$ & $27.9 \pm 6.2$ \\
\hline Smoker & $5.6 \%$ \\
\hline \multicolumn{2}{|l|}{ HRQOL \& comorbidities } \\
\hline Mean ODI score & $44.0 \pm 18$ \\
\hline Mean CCl score & $3.4 \pm 1.6$ \\
\hline \multicolumn{2}{|l|}{ Preop SRS-Schwab classification } \\
\hline Main type & $42 \%$ of type $\mathrm{N}$ \\
\hline PT modifier $>0$ & $66.3 \%$ \\
\hline SVA modifier $>0$ & $61.8 \%$ \\
\hline PI-LL modifier >0 & $65.0 \%$ \\
\hline \multicolumn{2}{|l|}{ Surgery parameters } \\
\hline Revision & $30.3 \%$ \\
\hline Mean no. of levels fused & $8.6 \pm 4.7$ \\
\hline Posterior only & $36.3 \%$ \\
\hline Posterior combined w/ TLIF/PLIF & $25.2 \%$ \\
\hline Posterior combined w/ ALIF/LLIF & $32.7 \%$ \\
\hline Other approaches & $5.7 \%$ \\
\hline \multicolumn{2}{|l|}{ rhBMP-2 parameters } \\
\hline rhBMP-2 use & $73.90 \%$ \\
\hline Mean total rhBMP-2 dose, $\mathrm{mg}$ & $23.6 \pm 16.6$ \\
\hline Mean total segmental rhBMP-2 dose, $\mathrm{mg} / \mathrm{level}$ & $3.1 \pm 3.3$ \\
\hline Mean posterior-only dose, mg/level & $2.9 \pm 2.7$ \\
\hline Mean posterior \& TLIF/PLIF dose, mg/level & $4.8 \pm 2.5$ \\
\hline Mean posterior \& ALIF/LLIF dose, mg/level & $4.0 \pm 2.7$ \\
\hline
\end{tabular}

$\mathrm{HRQOL}=$ health-related quality of life.

Mean values are presented as the mean \pm SD.

use significantly decreased for older patients, nonsmokers, patients with a history of cancer, primary surgery patients, and patients without a $3 \mathrm{CO}$. Finally, an increase in rhBMP-2 use between the first two periods was observed for each surgical approach but subsequently increased only for the posterior approach (Fig. 1).

\section{RhBMP-2 Dose Over Time by Approach}

The total rhBMP-2 dose per patient decreased over the 3 time periods ( $26.6 \mathrm{mg}$ vs $24.8 \mathrm{mg}$ vs $20.7 \mathrm{mg}$, $\mathrm{p}<0.001$ ). After stratification by location of use, the dose per level was stable for posterior use (3.1 mg vs $2.9 \mathrm{mg}$ vs $3.2 \mathrm{mg}$, p $=0.416)$, but decreased for TLIF/PLIF use $(5.6 \mathrm{mg}$ vs 5.3 $\mathrm{mg}$ vs $3.0 \mathrm{mg}, \mathrm{p}<0.001)$ and for ALIF/LLIF use (4.1 mg vs $5.5 \mathrm{mg}$ vs $3.4 \mathrm{mg}, \mathrm{p}<0.001$ ) (Fig. 2).

\section{Propensity-Matched Cohort Analysis}

After matching by preoperative alignment, 215 patients were included in each of the first 2 periods (2008-2011 and 2012-2015) (Fig. 3). No differences were observed in age $(56.6 \pm 15.4$ years vs $59.1 \pm 14.3$ years, $\mathrm{p}=0.082)$, preoperative spinal alignment, or surgical parameters.

An increase of rhBMP-2 use was observed between the 
TABLE 2. Comparison of BMP and no-BMP patient groups

\begin{tabular}{|c|c|c|c|}
\hline & BMP & No-BMP & \\
\hline No. of patients & $872(73.9 \%)$ & $308(26.1 \%)$ & - \\
\hline Mean age, yrs & $61.1 \pm 13.1$ & $57.9 \pm 17.5$ & $<0.001$ \\
\hline Mean BMI, kg/m² & $28.1 \pm 6.3$ & $27.2 \pm 5.9$ & 0.037 \\
\hline Smoker & $6 \%$ & $5.5 \%$ & 0.883 \\
\hline \multicolumn{4}{|l|}{ HRQOL \& comorbidities } \\
\hline Mean ODI score & $45.5 \pm 0.6$ & $44.4 \pm 19.3$ & 0.385 \\
\hline Mean CCl score & $1.9 \pm 1.7$ & $1.4 \pm 1.6$ & $<0.001$ \\
\hline \multicolumn{4}{|l|}{ Preop SRS-Schwab classification } \\
\hline Main type & $40 \%$ type $\mathrm{N}$ & $47 \%$ type $\mathrm{N}$ & 0.128 \\
\hline PT modifier $>0$ & $67.9 \%$ & $61.9 \%$ & 0.026 \\
\hline PI-LL modifier $>0$ & $66.6 \%$ & $60.6 \%$ & 0.161 \\
\hline SVA modifier $>0$ & $63.2 \%$ & $57.9 \%$ & 0.248 \\
\hline \multicolumn{4}{|l|}{ Surgical parameters } \\
\hline Revision (vs primary) & $30.70 \%$ & $29.20 \%$ & 0.665 \\
\hline Mean op time, mins & $445.7 \pm 182.2$ & $390.4 \pm 192.6$ & $<0.001$ \\
\hline Mean EBL, ml & $1699.8 \pm 1485.5$ & $1382.4 \pm 1299.3$ & 0.001 \\
\hline Mean no. of $3 \mathrm{CO}$ s per patient & $0.1 \pm 0.3$ & $0.2 \pm 0.4$ & 0.012 \\
\hline Mean no. of fused vertebral levels & $8.9 \pm 4.6$ & $7.9 \pm 4.8$ & 0.003 \\
\hline \multicolumn{4}{|l|}{ Surgery type } \\
\hline Posterior fusion only & $35.80 \%$ & $37.70 \%$ & \\
\hline Posterior fusion \& TLIF/PLIF & $26.70 \%$ & $20.80 \%$ & 0.402 \\
\hline Posterior fusion \& ALIF/LLIF & $31.70 \%$ & $35.70 \%$ & \\
\hline
\end{tabular}

Mean values are presented as the mean $\pm \mathrm{SD}$. Boldface type indicates statistical significance.

2008-2011 and 2012-2015 periods (66.0\% vs $80.5 \%$, p $=0.001)$. Patients in the former period experienced a significantly higher rate of revision surgery before 2 years ( $21.4 \%$ vs $13.0 \%, p=0.029)$ and a significantly higher rate of complications leading to a revision surgery. There was a trend toward a lower rate of pseudarthrosis for patients in the $2012-2015$ period ( $7 \%$ vs $4.2 \%, p=0.283$ ), but this difference did not reach statistical significance (Table 3). Finally, no patient in these first two periods developed new cancer within the 2 years following surgery.

\section{Discussion}

This study provides an assessment of the pattern of rhBMP-2 use by experienced ASD surgeons practicing at 17 sites throughout the US over the past decade. Overall, these deformity surgeons used rhBMP-2 in $74 \%$ of the ASD patients who underwent surgery between 2008 and 2018, which is a higher rate than currently reported in the literature. For example, De la Garza Ramos et al. reported a rate of rhBMP-2 use of $39.7 \%$ in ASD surgery based on data from the Nationwide Inpatient Database. ${ }^{20}$ The differing rates of rhBMP-2 use may be due, at least in part, to the different time intervals assessed (2002-2011 for the study from De la Garza Ramos et al. vs 2008-2018 for the current study).

By comparing BMP and no-BMP patients, we were able to identify factors associated with the choice to use rhBMP-2. Bess et al. previously assessed a subset of the current patients, those from the years $2008-2012,{ }^{21}$ and noted that rhBMP-2 use in ASD was associated with higher CCI scores. With the analysis of a larger cohort that includes the years 2008-2018, the present study provides additional baseline factors associated with rhBMP-2 use in ASD, including older age, higher BMI, and worse preoperative spinal alignment. In addition, patients for whom rhBMP-2 was used had longer operative times, higher EBL, and a greater number of levels fused, and ultimately had a greater magnitude of deformity correction. Of note, many of these factors have been previously described as risk factors of pseudarthrosis. ${ }^{22}$

The reasons for the changes over time in rhBMP-2 use observed in the present study are unclear. Although the high cost of rhBMP-2 may be a critical factor in deciding whether or not to use it, costs have remained relatively constant, since there has only very recently been a potential window for the development of a generic version. It is possible that the evolving perceptions and reporting of safety and efficacy of rhBMP-2 have impacted its application. When looking at the overall use of rhBMP-2 in the present study, an increase was observed between the 2008-2011 period and the 2012-2015 period, from $62.5 \%$ to $79 \%$. This increased use could reflect higher confidence in rhBMP-2 use within the ASD surgeon community. A few years after the initial promising results from industrysponsored studies that showed high rates of fusion with minimal associated complications in the field of degenerative disc disease, ${ }^{3,23-28}$ the first results of application for an 

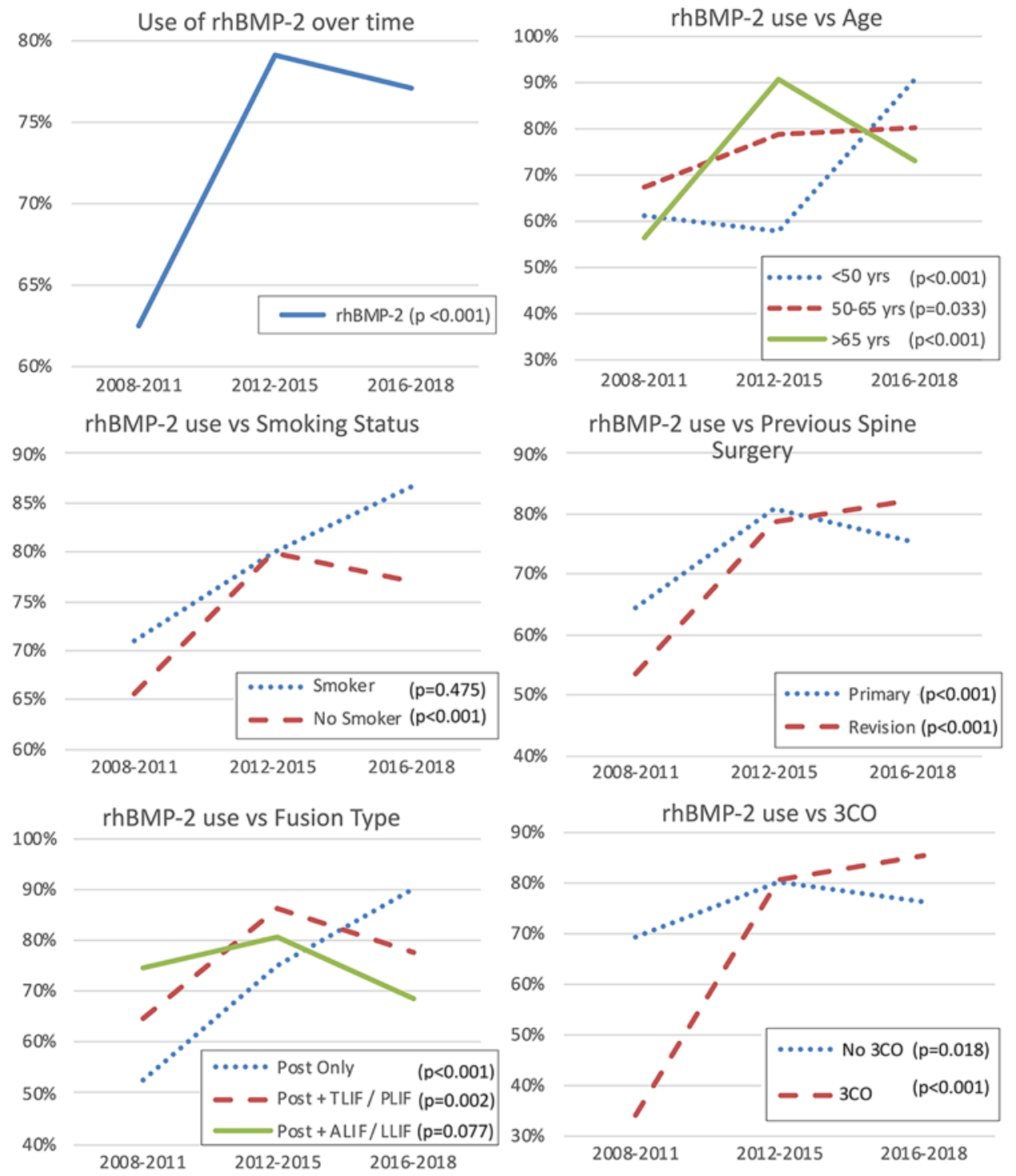

FIG. 1. RhBMP-2 uses across time periods: 2008-2011, 2012-2015, and 2016-2018. Post = posterior.

Total rhBMP-2 dose

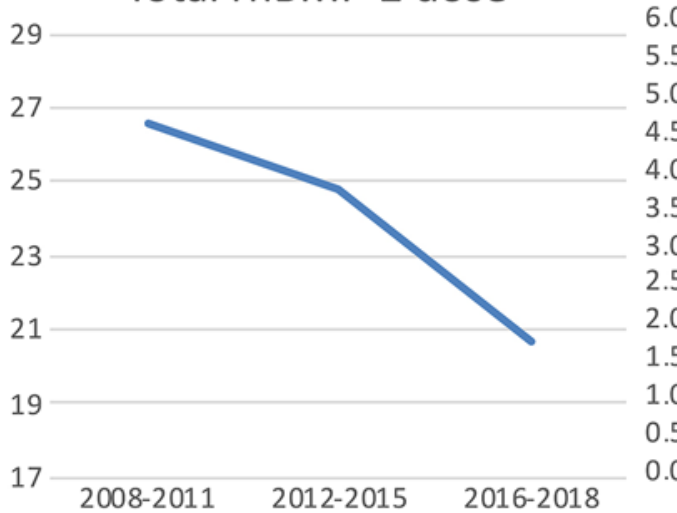

rhBMP-2 dose

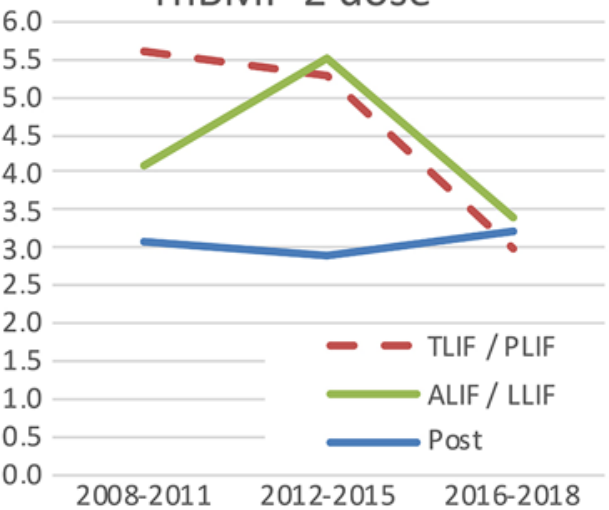

FIG. 2. RhBMP-2 doses across time periods: 2008-2011, 2012-2015, and 2016-2018. 

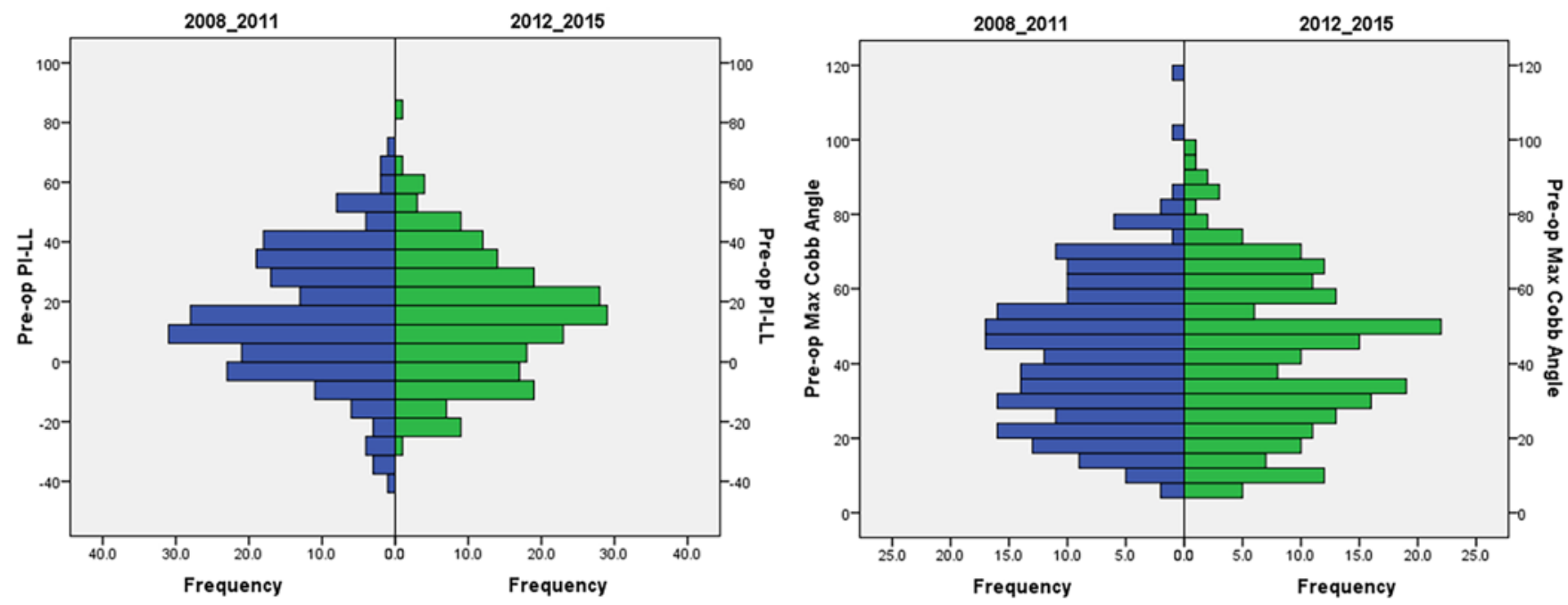

FIG. 3. 2008-2011 patients versus 2012-2015 patients. Distribution according to preoperative PI-LL and preoperative maximum Cobb angle after propensity matching.

TABLE 3. Complications of the 2008-2011 and 2012-2015 patients in the propensity-matched cohort $(n=215$ in each group)

\begin{tabular}{|c|c|c|}
\hline & \multicolumn{2}{|c|}{ No. of Patients (\%) } \\
\hline & 2008-2011 & 2012-2015 \\
\hline No. of patients & $52(24.2)$ & $34(15.8)$ \\
\hline Pseudarthrosis & $15(7)$ & $9(4.2)$ \\
\hline Implant & $14(6.5)$ & $10(4.7)$ \\
\hline Loose/dislocation & 2 & 1 \\
\hline Prominent implant & 2 & 2 \\
\hline Rod breakage & 9 & 7 \\
\hline Screw medial breach & 1 & 0 \\
\hline Radiographic & $18(8.4)$ & $14(6.5)$ \\
\hline Adjacent-segment disease & 0 & 1 \\
\hline Malalignment & 3 & 3 \\
\hline DJK/PJK & 11 & 10 \\
\hline Pseudarthrosis & 4 & 1 \\
\hline Surgical site infection & $6(2.8)$ & $5(2.3)$ \\
\hline Neurological & $8(3.7)$ & $2(0.9)$ \\
\hline Motor deficit & 3 & 0 \\
\hline Radiculopathy & 4 & 1 \\
\hline Spinal cord injury & 1 & 1 \\
\hline Wound & $2(0.9)$ & $0(0)$ \\
\hline Miscellaneous & $4(1.9)$ & $3(1.4)$ \\
\hline Bowel perforation & 1 & 0 \\
\hline Dural tear & 0 & 1 \\
\hline Retained sponge & 0 & 1 \\
\hline Pleural effusion & 1 & 0 \\
\hline Cholecystis & 2 & 0 \\
\hline Other & 0 & 1 \\
\hline
\end{tabular}

DJK = distal junctional kyphosis; $\mathrm{PJK}=$ proximal junctional kyphosis.
ASD population were published with very promising outcomes. In 2008, Mulconrey et al. published a prospective study showing a $100 \%$ fusion rate with posterior use of rhBMP-2. ${ }^{29}$ In 2009, Maeda et al. reported a significantly lower rate of pseudarthrosis when rhBMP-2 was used versus ICBG (4.3\% vs $28 \%){ }^{30}$ However, it was around this time that the first studies with warnings about rhBMP-2 were published. In June 2008, the FDA issued a public health notification informing of life-threatening complications with rhBMP-2 use in anterior cervical discectomy and fusion. ${ }^{31} \mathrm{~A}$ year later, the first meta-analysis with funnel plots reporting possible bias in initial industry-sponsored studies was published, ${ }^{32}$ and Carragee et al. reported a risk of adverse events associated with rhBMP-2 10 to 50 times the original estimates that were reported in the industry-sponsored peer-reviewed publications. ${ }^{10}$ Thus, despite the potentially concerning publications and warnings that emerged during that time, and the papers questioning the validity of the original industry-sponsored studies, the potential benefits continued to favor rhBMP-2 use among the enrolling deformity surgeons in the present study.

Analysis of the last two time periods, 2012-2015 and 2016-2018, demonstrated a stabilization in the overall use of rhBMP-2. It is possible that the ever-increasing downward pressures on healthcare cost may have constrained the growth in rhBMP-2 use, despite growing evidence of its effectiveness in the field of ASD..$^{21,33-35}$ This stabilization of use could also be related to concerns about the potential increased risk of malignancy as the FDA application for Amplify (Amplify Surgical, Inc.), a posterolateral graft implant with a dose of $40 \mathrm{mg} / \mathrm{level}$ of rhBMP-2, was rejected in 2011 for this specific reason. ${ }^{8,36}$ In 2013, the first two meta-analyses performed using data that were issued from the Yale University Open Data Access project reported a possibly higher risk of cancer in patients treated with rhBMP-2 and the possibility that this risk could be dose-dependent (10 of the 17 cancer cases were in the highest-dose arm of the trial). ${ }^{11,12}$ Although a recent study focused on high-dose rhBMP-2 use in spinal defor- 
mity patients strongly disfavored an association between cancer risk and rhBMP-2, ${ }^{37}$ it is possible that a combination of negative literature and cost-containment pressures may explain the plateau in rhBMP-2 use. The decrease in use for TLIF/PLIF compared with an increase in use for posterior-only fusion could be explained in the same fashion due to concerns raised in the literature regarding rhBMP-2 use in TLIF/PLIF, with reports of radiculitis and heterotopic bone formation with potential for compression of neural structures. ${ }^{38}$ Thankfully, the present study was reassuring, with no cases of malignancy and a lower rate of complications leading to revision surgery in patients in the 2012-2015 period compared with matched patients in the 2008-2011 period, despite the increased use of rhBMP-2.

With regard to rhBMP-2 dose, we reported lower values in the present study than those used in initial trials in the setting of degenerative disc disease; this included both posterior dose per level ( $3 \mathrm{mg}$ vs $12-40 \mathrm{mg}$ ) and interbody dose per level (4 mg vs 4.2-12 mg). ${ }^{11}$ The overall dose of rhBMP-2 decreased over time, and the average dose per level fused converged to $3 \mathrm{mg} / \mathrm{level}$. Multiple factors could account for this decline, including attempts to reduce cost, increased surgeon experience favoring acceptable fusion rates with lower doses, and concerns for potential associated complications.

Finally, surgeons increasingly used rhBMP-2 between the last two time periods for only younger patients, smokers, patients who received a $3 \mathrm{CO}$, and patients who underwent revision surgery. This was probably an attempt to only use rhBMP-2 for patients with the most positive benefit-risk balance as shown in the meta-analysis published by Laurie et al. in $2016 .{ }^{13}$

\section{Study Limitations}

The primary limitation of this study relates to its retrospective design. Although data were collected prospectively, the considerations of individual surgeons when deciding whether or not to use rhBMP-2 at the time of surgery were not documented. In addition, the potential impacts of rhBMP-2 use on clinical outcomes or fusion rates were not evaluated, as these were beyond the focus of the present study.

\section{Conclusions}

In this large multicenter series of surgically treated ASD patients, rhBMP-2 was most commonly used in older patients with greater comorbidities and worse sagittal alignment. Over the past decade, the use of BMP increased significantly for more severe adult deformities and for posterior-only fusions, but the dose decreased significantly over the same time. In order to have the most positive benefit-risk balance, future studies should investigate the characteristics of ASD patients who benefit the most from rhBMP-2 use.

\section{References}

1. Sasso RC, LeHuec JC, Shaffrey C. Iliac crest bone graft donor site pain after anterior lumbar interbody fusion: a prospective patient satisfaction outcome assessment. J Spinal Disord Tech. 2005;18(suppl):S77-S81.
2. Boden SD, Zdeblick TA, Sandhu HS, Heim SE. The use of rhBMP-2 in interbody fusion cages. Definitive evidence of osteoinduction in humans: a preliminary report. Spine (Phila Pa 1976). 2000;25(3):376-381.

3. Burkus JK, Gornet MF, Dickman CA, Zdeblick TA. Anterior lumbar interbody fusion using rhBMP-2 with tapered interbody cages. J Spinal Disord Tech. 2002;15(5):337-349.

4. Chrastil J, Low JB, Whang PG, Patel AA. Complications associated with the use of the recombinant human bone morphogenetic proteins for posterior interbody fusions of the lumbar spine. Spine (Phila Pa 1976). 2013;38(16):E1020E1027.

5. Rowan FE, O'Malley N, Poynton A. RhBMP-2 use in lumbar fusion surgery is associated with transient immediate postoperative leg pain. Eur Spine J. 2012;21(7):1331-1337.

6. Joseph V, Rampersaud YR. Heterotopic bone formation with the use of rhBMP2 in posterior minimal access interbody fusion: a CT analysis. Spine (Phila Pa 1976). 2007;32(25): 2885-2890.

7. McClellan JW, Mulconrey DS, Forbes RJ, Fullmer N. Vertebral bone resorption after transforaminal lumbar interbody fusion with bone morphogenetic protein (rhBMP-2). J Spinal Disord Tech. 2006;19(7):483-486.

8. Carragee EJ, Chu G, Rohatgi R, et al. Cancer risk after use of recombinant bone morphogenetic protein-2 for spinal arthrodesis. J Bone Joint Surg Am. 2013;95(17):1537-1545.

9. Burkus JK, Dryer RF, Peloza JH. Retrograde ejaculation following single-level anterior lumbar surgery with or without recombinant human bone morphogenetic protein-2 in 5 randomized controlled trials: clinical article. J Neurosurg Spine. 2013;18(2):112-121.

10. Carragee EJ, Hurwitz EL, Weiner BK. A critical review of recombinant human bone morphogenetic protein-2 trials in spinal surgery: emerging safety concerns and lessons learned. Spine J. 2011;11(6):471-491.

11. Fu R, Selph S, McDonagh M, et al. Effectiveness and harms of recombinant human bone morphogenetic protein-2 in spine fusion: a systematic review and meta-analysis. Ann Intern Med. 2013;158(12):890-902.

12. Simmonds MC, Brown JVE, Heirs MK, et al. Safety and effectiveness of recombinant human bone morphogenetic protein-2 for spinal fusion: a meta-analysis of individualparticipant data. Ann Intern Med. 2013;158(12):877-889.

13. Laurie AL, Chen Y, Chou R, Fu R. Meta-analysis of the impact of patient characteristics on estimates of effectiveness and harms of recombinant human bone morphogenetic protein-2 in lumbar spinal fusion. Spine (Phila Pa 1976). 2016; 41(18):E1115-E1123.

14. Glassman SD, Carreon LY, Djurasovic M, et al. RhBMP-2 versus iliac crest bone graft for lumbar spine fusion: a randomized, controlled trial in patients over sixty years of age. Spine (Phila Pa 1976). 2008;33(26):2843-2849.

15. Michielsen J, Sys J, Rigaux A, Bertrand C. The effect of recombinant human bone morphogenetic protein-2 in singlelevel posterior lumbar interbody arthrodesis. J Bone Joint Surg Am. 2013;95(10):873-880.

16. Scheer JK, Oh T, Smith JS, et al. Development of a validated computer-based preoperative predictive model for pseudarthrosis with $91 \%$ accuracy in 336 adult spinal deformity patients. Neurosurg Focus. 2018;45(5):E11.

17. Smith JS, Shaffrey E, Klineberg E, et al. Prospective multicenter assessment of risk factors for rod fracture following surgery for adult spinal deformity. J Neurosurg Spine. 2014; 21(6):994-1003

18. Poorman GW, Jalai CM, Boniello A, et al. Bone morphogenetic protein in adult spinal deformity surgery: a meta-analysis. Eur Spine J. 2017;26(8):2094-2102.

19. Schwab F, Ungar B, Blondel B, et al. Scoliosis Research Society-Schwab adult spinal deformity classification: a validation study. Spine (Phila Pa 1976). 2012;37(12):1077-1082. 
20. De la Garza Ramos R, Nakhla J, Bhashyam N, et al. Trends in the use of bone morphogenetic protein-2 in adult spinal deformity surgery: a 10 -year analysis of 54054 patients. Int $J$ Spine Surg. 2018;12(4):453-459.

21. Bess $\mathrm{S}$, Line BG, Lafage V, et al. Does recombinant human bone morphogenetic protein-2 use in adult spinal deformity increase complications and are complications associated with location of rhBMP-2 use? A prospective, multicenter study of 279 consecutive patients. Spine (Phila Pa 1976). 2014;39(3): 233-242.

22. How NE, Street JT, Dvorak MF, et al. Pseudarthrosis in adult and pediatric spinal deformity surgery: a systematic review of the literature and meta-analysis of incidence, characteristics, and risk factors. Neurosurg Rev. 2019;42(2):319-336.

23. Boden SD, Kang J, Sandhu H, Heller JG. Use of recombinant human bone morphogenetic protein-2 to achieve posterolateral lumbar spine fusion in humans: a prospective, randomized clinical pilot trial: 2002 Volvo Award in clinical studies. Spine (Phila Pa 1976). 2002;27(23):2662-2673.

24. Burkus JK, Transfeldt EE, Kitchel SH, et al. Clinical and radiographic outcomes of anterior lumbar interbody fusion using recombinant human bone morphogenetic protein-2. Spine (Phila Pa 1976). 2002;27(21):2396-2408.

25. Haid RW Jr, Branch CL Jr, Alexander JT, Burkus JK. Posterior lumbar interbody fusion using recombinant human bone morphogenetic protein type 2 with cylindrical interbody cages. Spine J. 2004;4(5):527-539.

26. Burkus JK, Sandhu HS, Gornet MF, Longley MC. Use of rhBMP-2 in combination with structural cortical allografts: clinical and radiographic outcomes in anterior lumbar spinal surgery. J Bone Joint Surg Am. 2005;87(6):1205-1212.

27. Glassman SD, Dimar JR, Carreon LY, et al. Initial fusion rates with recombinant human bone morphogenetic protein-2/compression resistant matrix and a hydroxyapatite and tricalcium phosphate/collagen carrier in posterolateral spinal fusion. Spine (Phila Pa 1976). 2005;30(15):1694-1698.

28. Dimar JR, Glassman SD, Burkus KJ, Carreon LY. Clinical outcomes and fusion success at 2 years of single-level instrumented posterolateral fusions with recombinant human bone morphogenetic protein-2/compression resistant matrix versus iliac crest bone graft. Spine (Phila Pa 1976). 2006;31(22): 2534-2540.

29. Mulconrey DS, Bridwell KH, Flynn J, et al. Bone morphogenetic protein (RhBMP-2) as a substitute for iliac crest bone graft in multilevel adult spinal deformity surgery: minimum two-year evaluation of fusion. Spine (Phila Pa 1976). 2008; 33(20):2153-2159.

30. Maeda T, Buchowski JM, Kim YJ, et al. Long adult spinal deformity fusion to the sacrum using rhBMP-2 versus autogenous iliac crest bone graft. Spine (Phila Pa 1976). 2009; 34(20):2205-2212.

31. FDA issues alert on rhBMP and cervical spine fusion. Lippincott's Bone Jt Newsl. 2008;14(9):104-105.

32. Agarwal R, Williams K, Umscheid CA, Welch WC. Osteoinductive bone graft substitutes for lumbar fusion: a systematic review. J Neurosurg Spine. 2009;11(6):729-740.

33. Schmitt PJ, Kelleher JP, Ailon T, et al. Long-segment fusion for adult spinal deformity correction using low-dose recombinant human bone morphogenetic protein-2: a retrospective review of fusion rates. Neurosurgery. 2016;79(2):212-221.

34. Ruofeng Y, Cohen JR, Buser Z, et al. Trends of posterior long segment fusion with and without recombinant human bone morphogenetic protein 2 in patients with scoliosis. Global Spine J. 2016;6(5):422-431.

35. Paul JC, Lonner BS, Vira S, et al. Use of recombinant bone morphogenetic protein is associated with reduced risk of reoperation after spine fusion for adult spinal deformity. Spine (Phila Pa 1976). 2016;41(1):E15-E21.

36. Devine JG, Dettori JR, France JC, et al. The use of rhBMP in spine surgery: is there a cancer risk? Evid Based Spine Care J. 2012;3(2):35-41.

37. Baldus C, Kelly MP, Yanik EL, et al. Incidence of cancer in spinal deformity patients receiving high-dose $(\geq 40 \mathrm{mg})$ bone morphogenetic protein (rhBMP-2). Spine (Phila Pa 1976). 2017;42(23):1785-1791.

38. Rosen CD, Kiester PD, Lee TQ. Pseudo-pedicle heterotopic ossification from use of recombinant human bone morphogenetic protein 2 (rhBMP-2) in transforaminal lumbar interbody fusion cages. Am J Orthop. 2018;47(1). Accessed April 15, 2021. https://www.mdedge.com/surgery/ article/197808/spine/pseudo-pedicle-heterotopic-ossificationuse-recombinant-human-bone

\section{Disclosures}

Dr. Smith: consultant for Zimmer Biomet, NuVasive, Cerapedics, DePuy Synthes, Stryker, and Carlsmed; direct stock ownership in NuVasive and Alphatec; clinical or research support for the study described from DePuy Synthes; support of non-study-related clinical or research effort from DePuy Synthes, NuVasive, and AO Spine; and royalties from Zimmer Biomet, NuVasive, and Thieme. Dr. Bess: consultant for K2M Stryker and Miru; direct stock ownership in Progenerative Medical and Carlsmed; patent holder with K2M Stryker and NuVasive; clinical or research support for the study described from ISSGF, K2M Stryker, NuVasive, and DePuy Synthes; support of non-study-related clinical or research effort from ISSGF, NuVasive, Medtronic, DePuy Synthes, K2M Stryker, SI-Bone, and SeaSpine; speakers bureau for K2M Stryker; and royalties from K2M Stryker and NuVasive. Dr. Klineberg: consultant for DePuy Synthes, Stryker, and Medicrea/Medtronic; honoraria from AO Spine; and fellowship grant from AO Spine. Dr. Ames: employee of UCSF; royalties from Stryker, Biomet Zimmer Spine, DePuy Synthes, NuVasive, Next Orthosurgical, K2M, and Medicrea; consultant for DePuy Synthes, Medtronic, Medicrea, and K2M; research support from DePuy Synthes, Titan Spine, and ISSG; editorial board of Operative Neurosurgery; grant funding from SRS; executive committee of ISSG; and director of Global Spinal Analytics. Dr. Mundis: consultant for NuVasive, Viseon, SeaSpine, and Carlsmed; direct stock ownership in NuVasive, SeaSpine, Alphatec, and Surgalign; patent holder with Stryker, SeaSpine, and NuVasive; and royalties from NuVasive and Stryker. Dr. Kim: royalties from Zimmer Biomet and K2M Stryker; clinical or research support for the study described from ISSGF; and fellowship grant to hospital from AO Spine. Mr. R Lafage: ownership in Nemaris. Dr. Gupta: royalties from DePuy, Innomed, and Globus; consultant for DePuy, Medtronic, Globus, and Alphatec; honoraria from AO Spine; direct stock ownership in $\mathrm{J} \& \mathrm{~J}$ and $\mathrm{P} \& \mathrm{G}$; and travel for faculty/meeting from Scoliosis Research Society, AO Spine, DePuy, Globus, Medtronic, Medicrea, Mizuho, and Alphatec. Dr. Burton: direct stock ownership in Progenerative Medical; royalties from DePuy; clinical or research support for the study described from ISSGF; and consultant for Globus. Dr. Shaffrey: consultant for Medtronic, NuVasive, and SI-Bone; direct stock ownership in NuVasive; patent holder with Medtronic, NuVasive, and Zimmer Biomet; and royalties from NuVasive. Dr. Schwab: consultant for Globus Medical and Zimmer Biomet; royalties from Zimmer Biomet and Medtronic; and executive committee of the International Spine Study Group. Dr. V Lafage: consultant for Globus Medical; royalties from NuVasive; honoraria from DePuy Synthes and Implanet; and direct stock ownership in Nemaris.

\section{Author Contributions}

Conception and design: Bannwarth. Acquisition of data: Smith, Bess, Klineberg, Ames, Mundis, Kim, Gupta, Burton, Shaffrey, Schwab. Analysis and interpretation of data: Bannwarth. Drafting the article: Bannwarth. Critically revising the article: Smith, V Lafage. Reviewed submitted version of manuscript: Smith, 
Bess, Klineberg, Ames, Mundis, Kim, R Lafage, Gupta, Burton, Schwab. Statistical analysis: Bannwarth, R Lafage. Administrative/technical/material support: R Lafage. Study supervision: V Lafage.

\section{Supplemental Information}

Previous Presentations

Portions of this work were presented in abstract form at the North American Spine Society 34th Annual Meeting, Chicago, Illinois, October 25-28, 2019.

\section{Correspondence}

Mathieu Bannwarth: University Hospital of Reims, Hopital Maison Blanche, Reims, France. mathieu.bannwarth@neurochirurgie.fr. 